\title{
Surgical and postmortem pathology studies: contribution for the investigation of temporal lobe epilepsy
}

\author{
Patologia cirúrgica e post mortem: contribuição para a investigação da epilepsia do \\ lobo temporal \\ Luís Otávio Sales Ferreira Caboclo', Rafael Scarpa Neves', Anaclara Prada Jardim', \\ Ana Paula Andrade Hamad', Ricardo Silva Centeno', Carmen Lucia Penteado Lancellotti², \\ Carla Alessandra Scorza ${ }^{3}$, Esper Abrão Cavalheiro ${ }^{3}$, Elza Márcia Targas Yacubian', Américo Ceiki Sakamoto ${ }^{4}$
}

\begin{abstract}
Pathology studies in epilepsy patients bring useful information for comprehending the physiopathology of various forms of epilepsy, as well as aspects related to response to treatment and long-term prognosis. These studies are usually restricted to surgical specimens obtained from patients with refractory focal epilepsies. Therefore, most of them pertain to temporal lobe epilepsy (TLE) with mesial temporal sclerosis (MTS) and malformations of cortical development (MCD), thus providing information of a selected group of patients and restricted regions of the brain. Postmortem whole brain studies are rarely performed in epilepsy patients, however they may provide extensive information on brain pathology, allowing the analysis of areas beyond the putative epileptogenic zone. In this article, we reviewed pathology studies performed in epilepsy patients with emphasis on neuropathological findings in TLE with MTS and MCD. Furthermore, we reviewed data from postmortem studies and discussed the importance of performing these studies in epilepsy populations.
\end{abstract}

Key words: epilepsy, temporal lobe, mesial temporal sclerosis, pathology, surgical.

\section{RESUMO}

Estudos de patologia em pacientes com epilepsia trazem informações úteis para compreender a fisiopatologia de várias formas de epilepsia, bem como aspectos relacionados ao tratamento e ao prognóstico a longo prazo. Esses estudos são usualmente restritos a espécimes cirúrgicos obtidos de pacientes com epilepsias focais refratárias. Portanto, a maioria diz respeito à epilepsia do lobo temporal (ELT) com esclerose mesial temporal (EMT) e às malformações do desenvolvimento cortical (MDC). Desse modo, fornecem informações sobre um grupo selecionado de pacientes e sobre regiões restritas do cérebro. Raramente são realizados estudos post mortem do cérebro inteiro em pacientes com epilepsia; entretanto, eles podem prover informações relevantes sobre patologia cerebral, permitindo a análise de áreas além da zona epileptogênica putativa. Neste artigo, foram revisados estudos de patologia feitos em pacientes com epilepsia, com ênfase nos achados neuropatológicos em ELT com EMT e MDC. Foram revisados, ainda, dados de estudos post mortem e discutiu-se a importância da realização desses estudos em populações de pessoas com epilepsia.

Palavras-Chave: epilepsia do lobo temporal, esclerose mesial temporal, patologia cirúrgica.

Diagnostic evaluation of epilepsy patients includes clinical history, neurological examination, seizure semiology analysis, neuropsychological assessment, as well as auxiliary diagnostic tools, such as electroencephalogram (EEG), structural neuroimaging (computed tomography and magnetic resonance imaging), and functional neuroimaging (functional magnetic resonance, single-photon emission computed tomography, positron emission tomography, and magnetic resonance spectroscopy).

Investigation of patients with both focal and generalized epileptic syndromes may also include, whether for clinical or research purposes, pathological studies of the brain

1Department of Neurology and Neurosurgery, Universidade Federal de São Paulo, São Paulo SP, Brazil;

${ }^{2}$ Departament of Pathology, Associação Fundo de Incentivo à Pesquisa (AFIP); Santa Casa de São Paulo, São Paulo SP, Brazil;

${ }^{3}$ Division of Experimental Neurology, Department of Neurology and Neurosurgery, Universidade Federal de São Paulo, São Paulo SP, Brazil;

${ }^{4}$ Department of Neuroscience and Behavioral Science, Faculdade de Medicina da Universidade de São Paulo, Ribeirão Preto SP, Brazil.

Correspondence: Luís Otávio Sales Ferreira Caboclo; Unidade de Pesquisa e Tratamento das Epilepsias (UNIPETE), Hospital São Paulo; Rua Napoleão de Barros 737 /13andar; 04024-002 São Paulo SP - Brasil; E-mail: locaboclo@ig.com.br

Support: Coordenação de Aperfeiçoamento de Pessoal de Nivel Superior (CAPES); Conselho Nacional de Desenvolvimento Científico e Tecnológico (CNPq); Fundação de Amparo à Pesquisa do Estado de São Paulo (FAPESP); Instituto Nacional de Neurociência Translacional (INNT).

Conflict of interest: There is no conflict of interest to declare.

Received 14 March 2012; Received in final form 10 April 2012; Accepted 17 April 2012 
tissue. These studies may bring useful information for comprehending the physiopathology of various epilepsy forms, as well as aspects related to response to treatment and long-term prognosis.

\section{PATHOLOGY STUDIES IN EPILEPSY PATIENTS}

Pathology studies in epilepsy patients are usually restricted to surgical specimens obtained from patients with refractory focal epilepsies. Therefore, the vast majority address temporal lobe epilepsy (TLE), due to hippocampal sclerosis (HS), and focal epilepsies, due to malformations of cortical development (MCD), given that these pathologies constitute the most common etiologies of surgically amenable epilepsies ${ }^{1}$. These studies thus provide information of a selected group of patients and restricted regions of the brain. Nevertheless, they can bring important data concerning the physiopathology of focal epilepsies and also about factors related to postsurgical prognosis in these patients.

Whole brain studies in postmortem examination are rarely performed in epilepsy patients, but they may provide extensive information on brain pathology $y^{2,3}$, allowing the analysis of areas beyond the putative epileptogenic zone ${ }^{4,5}$. However, this sort of study is rare even in centers specialized in the care of epilepsy patients ${ }^{6}$.

\section{TEMPORAL LOBE EPILEPSY AND MESIAL TEMPORAL SCLEROSIS}

TLE is the most frequent focal epileptic syndrome in adults $^{7}$. TLE patients are classified, according to clinical and electrographic features, in two separate groups: mesial TLE and lateral or neocortical TLE ${ }^{8}$. Mesial TLE expresses itself through epileptic seizures originated in mesial structures of the temporal lobe, usually the hippocampal formation and occasionally the amygdala ${ }^{6}$. HS is the most frequent underlying pathological substrate in TLE ${ }^{9}$. Mesial TLE with HS constitutes a distinct epileptic syndrome, with well-defined clinical, neuroimaging, and prognostic features ${ }^{6}$.

Pathological studies of the temporal lobe tissue resected during surgeries for treatment of drug-resistant mesial TLE revealed a pattern of sclerosis or neuronal loss in the hippocampal formation 9 . The hippocampus in these patients presents neuronal loss in subfields CA 1 and 4, with relative sparing of CA 2 and granular cells of the dentate gyrus (DG). Reactive astrogliosis is also observed, which associated with neuronal loss leads to the aspect of atrophy and tissue hardening. This pathological aspect was described in $1880^{10}$ and later named Ammon's Horn Sclerosis². The more marked neuronal loss in subfields CA 1 and 4 was confirmed by quantitative pathological studies ${ }^{11,12}$. Besides the hippocampal formation, other mesial structures may present neuronal loss and gliosis, including the entorhinal cortex ${ }^{13}$ and the amygdala $^{14,15}$. The expression mesial temporal sclerosis (MTS) was introduced as an alternative to HS, denoting atrophy of other structures beyond the hippocampal formation ${ }^{16}$. However, its association with injury of other mesial structures should be confirmed by pathological examination, whether in surgical or autopsy specimens, so that MTS is used properly ${ }^{9}$.

TLE and MTS association is well-established, although it is still discussed if MTS constitutes the indispensable substrate for seizure generation of it. On the other hand, it is the consequence of repeated epileptic seizures ${ }^{9}$. The role of an initial precipitant insult (IPI) such as febrile seizures or traumatic brain injury is also yet to be defined. It is possible that, in MTS, the neuronal loss encountered in surgical specimens may represent a combination of an acute loss by the time of the IPI and additional losses resulting from repeated seizures ${ }^{17}$.

MTS is not inexorably associated with TLE. There is a group of patients in whom MTS is indeed associated with the typical features of mesial TLE. In these patients, neuronal loss and synaptic reorganization probably constitute the physiopathological abnormality that originates clinical seizures. This situation is sometimes referred to as "primary HS”. However, a distinct group of patients may be identified, in whom pathological features compatible with MTS are observed, though without the typical clinical characteristics of TLE. In this latter group, MTS may be secondary to seizures originated from extratemporal cortical areas ${ }^{5,18}$.

In addition, MTS is not necessary for the occurrence of temporal lobe seizures. Other etiologies may be identified, such as MCD or tumors. Yet, in some patients, a clinical syndrome undistinguishable from TLE with MTS is observed, though with no signs of MTS in neuroimaging studies and pathological examination. This condition has been named "paradoxical TLE"18.

There is enough data from animal models ${ }^{19}$ and human studies $^{20,21}$ to affirm that prolonged seizures and status epilepticus may injury the hippocampus and eventually lead to MTS. However, in humans, MTS is not the inevitable consequence of repeated seizures and the exact time course of the relation between MTS and the occurrence of seizures is not precisely defined ${ }^{5}$.

\section{TEMPORAL LOBE EPILEPSY: SURGICAL} PATHOLOGY

In TLE patients with drug-resistant seizures, surgery is better than clinical treatment with respect to seizure control and quality of life ${ }^{22}$. TLE with MTS constitutes the most frequent indication of surgical treatment in adults ${ }^{7}$. Approximately two third of patients become seizure free 
after surgery ${ }^{7,23-25}$. However, the remaining third continues to have disabling seizures, and this number seems to increase with longer follow-up periods ${ }^{26-28}$.

Several features have been studied as prognostic factors, but conflicting conclusions have been reached, probably due to methodological issues and population heterogeneity in different studies ${ }^{25,27,28}$. Bilateral hippocampal abnormalities and extratemporal injuries have been implicated in poor surgical prognosis in operated TLE patients ${ }^{25,29}$. Therefore, pathology studies in TLE with MTS may bring important contributions for the elucidation of the mechanisms involved in the response to surgical treatment.

The pattern of neuronal loss in the resected hippocampal formation may correlate with prognosis. Atypical patterns of MTS have been recognized for decades, initially on postmortem pathology series ${ }^{2}$ and later in surgically resected hippocampal specimens ${ }^{30}$. These atypical patterns may be associated with worse surgical outcome $\mathrm{e}^{12,31}$. Their identification before surgery, through advanced neuroimaging techniques ${ }^{32}$, might help defining surgical programming.

Blumcke et al. ${ }^{12}$ proposed a new system of histological classification in TLE patients submitted to surgical treatment. They studied surgical specimens from 178 patients, who were divided into five groups, according to the pattern of neuronal loss in the hippocampus and DG:

- no MTS;

- MTS type 1a: classic hippocampal sclerosis, characterized by neuronal loss in subfields CA 1 and 4, with more marked loss in CA 1;

- MTS type 1b: severe hippocampal sclerosis, with marked diffuse neuronal loss;

- $\quad$ MTS type 2: CA 1 sclerosis, with neuronal loss practically restricted to $\mathrm{CA} 1$;

- MTS type 3: end folium sclerosis, with neuronal loss restricted to the DG hilus.

After a minimum six-month follow-up, MTS patterns correlated to prognosis with respect to seizures: patients with MTS types $1 \mathrm{a}$ and $\mathrm{b}$ had the best prognosis ( 86 and $85 \%$ of patients free of seizures, respectively), followed by patients with no MTS (71\%). It is worth remarking that 12 out of the 34 patients with no MTS had other lesions in close proximity with the hippocampus, including slow growth tumors and focal cortical dysplasia. Patients with MTS types 2 and 3 had the worst prognosis (50 and 43\% free of seizures, respectively). The correlation between MTS and prognosis persisted after one year of follow-up.

Thom et al. ${ }^{33}$ reviewed and classified the patterns of MTS in 165 operated TLE patients. Atypical patterns of MTS, including end folium sclerosis and CA 1 predominant (CA1p) sclerosis, were found in $28 \%$ of patients, whereas 18 patients had no pathological signs of MTS. Postsurgical prognosis was worse in patients with CA 1 predominant neuronal loss, as in those without signs of MTS. Jardim et al. ${ }^{34}$ studied 66 TLE with MTS patients, analyzing clinical characteristics and MTS patterns. Occurrence of initial precipitating insult, as well as better postoperative seizure control, was associated with classical (type 1a) and severe (type 1b) patterns of MTS. These studies confirmed that the recognition and definition of different patterns of neuronal loss (Fig 1) in the hippocampus of TLE patients submitted to surgical treatment may be useful in the definition of postsurgical prognosis.

Hence, other neuropathological findings found in surgical specimens may bring information regarding epileptogenesis in TLE or provide data relevant to surgical prognosis. Granule cell dispersion (GCD) and temporal lobe sclerosis (TLS) are among these findings.

GCD is a common phenomenon, occurring in up to $40 \%$ of the hippocampi of TLE patients ${ }^{6,12,35}$. It is characterized by broadening of the granule cell layer of the $\mathrm{DG}^{12,36}$. Criteria for determining dispersion vary from qualitative impressions of the layer width to more objective quantitative measures ${ }^{37}$. In addition to GCD, the DG may present a bilaminar pattern, defined as two parallel layers of granule cells, the inner band considered as remnant of the original DG and an additional ectopic outer band towards the molecular layer ${ }^{37}$ (Fig 2).

Houser first described GCD in TLE patients' hippocampi, in which the border between granule cell and molecular layers was not distinct, with numerous granule cell somata extending into the molecular layer. GCD may depend on the neuronal loss in the DG hilus ${ }^{38}$, although it may also be observed in patients with widespread cortical malformation, even in the

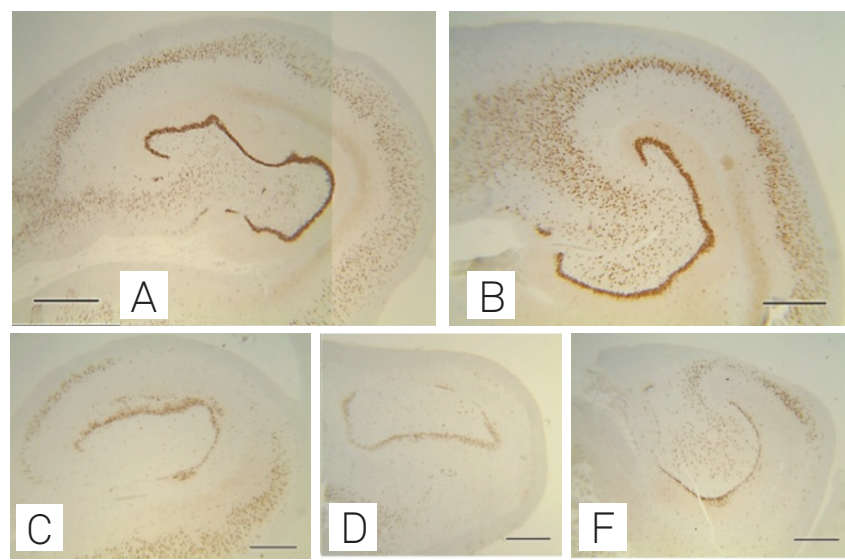

Fig 1. Hippocampal formation in control and temporal lobe epilepsy patients and patterns of hippocampal sclerosis (all NeuN-stained sections). (A) Control specimen. (B) No mesial temporal sclerosis: no loss of neurons detected in all subfields (hippocampus subfields 1 to 4). (C) Mesial temporal sclerosis type 1a (classic hippocampal sclerosis): significant neuronal loss in hippocampus subfields 1 and 4 with relative sparing of neurons in hippocampus subfield 2. (D) Mesial temporal sclerosis type $1 \mathrm{~b}$ (severe hippocampal sclerosis): neuronal loss in all subfields and in the dentate gyrus. (E) Mesial temporal sclerosis type 2 (hippocampus subfield 1-sclerosis): neuronal loss predominating in hippocampus subfield 1. Scale bars: $1 \mathrm{~mm}$. 

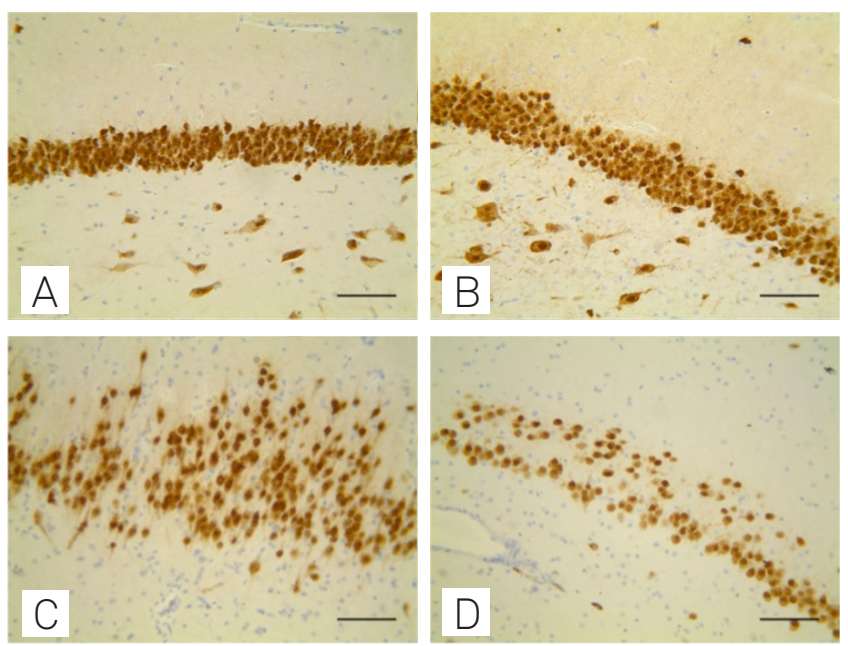

Fig 2. Histopathological findings in dentate gyrus of controls and temporal lobe epilepsy patients (NeuN-stained sections). (A) Control. (B) No granule cell dispersion: granule cells are densely packed and have a distinct border with the molecular layer. (C) Granule cell dispersion: the cells are dispersed and spread into the molecular layer. (D) Bilamination: granule cells are dispersed, but with a cell free zone between both layers. Scale bars: $100 \mu \mathrm{m}$

absence of hippocampal cell loss, suggesting a maldevelopment disorder ${ }^{39}$. Early seizure onset or status epilepticus at an initial stage of the disease have been associated with $\mathrm{GCD}^{40,41}$. GCD may be a consequence of enhanced proliferation of granule cell precursors as a result of seizures ${ }^{42,43}$. Its clinical relevance is uncertain, as is its relation to surgical prognosis ${ }^{12,33,37}$.

Dysmorphic neurons and interneurons may be encountered in the DG of TLE with MTS patients, along with $\mathrm{GCD}^{44-46}$. Also, CD34-positive balloon cells have been described as being associated with $\mathrm{GCD}^{47}$, which raises the hypothesis of focal cortical dysplasia (FCD) localized in the DG in these patients. On the other hand, CD34 expression may just be a transitory phenomenon in the GCD process, possibly related to increase in neurogenesis and proliferation of progenitor cells of the glia ${ }^{43}$.

Neuronal loss and gliosis, which were observed in the hippocampal formation of TLE patients submitted to surgical treatment, may extend beyond this formation and involve the uncus, amygdala, parahippocampal gyrus, and temporal neocortex ${ }^{48}$. However, the frequency, severity, and distribution of neuronal loss and gliosis in the temporal neocortex characterizing TLS - are yet to be precisely defined.

Thom et al. ${ }^{49}$ studied 272 TLE with MTS patients submitted to surgical treatment for refractory seizures. In 30 patients (11\%), histological pattern compatible with TLS was identified: neuronal loss in layers II and III of the temporal cortex, with correspondent laminar gliosis in those affected by neuronal loss. Neuronal loss and gliosis were typically associated with structural abnormalities in layer II, such as abnormal neuronal orientation and aggregation. In $40 \%$ of the cases, a TLS gradient was observed with more marked involvement toward the temporal pole, which would suggest involvement of hippocampal projection pathways. Febrile seizures were more frequent in patients with TLE when compared to those without this pathological abnormality (73 and 36\%, respectively). There was no difference between the two groups regarding postsurgical prognosis. The authors concluded that in these series of TLE with MTS patients, TLS was considered as part of the MTS spectrum, not as a second lesion associated with HS or dual pathology. Structural abnormalities observed in layer II probably represent organizational alterations related to the process of TLS, however they do not constitute a MCD in its strict sense.

Neuroimaging studies revealed that abnormalities in the temporal lobe may coexist with MTS ${ }^{50,51}$. The temporal pole in TLE with MTS patients may present signal abnormalities in up to $75 \%$ of the cases ${ }^{52}$. Signal abnormalities and atrophy of the temporal pole are ipsilateral to MTS in the majority of patients $\mathrm{s}^{53}$. Despite the alterations observed in neuroimaging studies, neuropathological studies in patients with such alterations have been inconclusive ${ }^{51}$. Depth EEG studies revealed that the temporal pole cortex may play a pivotal role in originating seizures in TLE patients, with ictal discharges preceding or occurring simultaneously with discharges originated from the ipsilateral hippocampus ${ }^{50}$. In addition to temporal lobe cortex alterations, other abnormalities may be observed in the extratemporal cortex in patients with TLE-MTS ${ }^{54}$.

The association between temporal lobe development abnormalities - including focal cortical dysplasia (FCD) - and MTS is also recognized ${ }^{55-57}$. Therefore, although MTS is more commonly seen as an acquired pathology, presence of hippocampal malformation as a substrate for further development of MTS and TLE is frequently questioned ${ }^{55,56,58}$.

\section{POSTMORTEM PATHOLOGY STUDIES}

Postmortem pathology studies, although rare in epilepsy patients ${ }^{6}$, may provide very useful information, especially when pathological findings are correlated to clinical and neuroimaging data.

Pathological studies in TLE with MTS are usually limited to the examination of one of the hippocampi obtained during surgery for treatment of drug-resistant epilepsy. This approach bears two important limitations: firstly, it does not allow the study of other areas of the brain, particularly the contralateral hippocampus; and secondly, only highly-selected patients, fulfilling strict criteria for indication of surgical treatment, are included in these studies ${ }^{59}$. On the other hand, postmortem studies provide global access to brain tissue, including the hippocampus which is contralateral to that primarily defined as being epileptogenic in TLE patients ${ }^{5,6}$.

Margerison and Corsellis ${ }^{2}$, in a seminal paper published in 1966, studied the brains of 55 epilepsy patients, with 
emphasis on the temporal lobes. Twenty-six patients had TLE. Both hippocampi were examined in all cases, and MTS was identified in 36 of the 55 patients. Fourteen out of the 36 had a pattern compatible with end folium gliosis (EFG), while 22 showed the classical features of HS. Among the latter 22 patients, 4 had bilateral and 18 unilateral HS, including eight with contralateral EFG. Overall, almost half of the patients (17/36) had bilateral hippocampal abnormalities, whether classical HS or EFG.

Postmortem series may also bring information on the possible relation between repeated seizures and neuronal loss in the hippocampus. Dam ${ }^{60}$ studied the brains of $20 \mathrm{ep-}$ ilepsy patients and quantified the hippocampal neurons. Epilepsy patients had fewer neurons in their hippocampi, when compared to controls. Neuronal loss predominated in the end folium and was influenced by the occurrence of generalized seizures and duration of epilepsy. Nixon et al. ${ }^{61}$ reported the case of a 35-year-old man who died as a consequence of status epilepticus. Postmortem neuropathological examination disclosed marked neuronal loss in both hippocampi, which was considered a direct result of the status epilepticus, since the patient had no previous history of epilepsy, the first magnetic resonance imaging was normal, and there was no evidence of hypoxic lesions or infectious encephalitis. Pohlmann-Eden et al. ${ }^{20}$ reported the case of a man who suffered a prolonged status epilepticus, in a five-month period. Sequential magnetic resonance imaging exams showed signs of progressive lesion in both hippocampi, which was confirmed by autopsy, revealing bilateral HS and thus providing support for the hypothesis that prolonged status epilepticus might cause hippocampal lesion in humans.

There is however evidence on the contrary. Thom et al. ${ }^{5}$ conducted a stereological analysis of the hippocampi of 28 patients with poorly controlled seizures, and identified a group of patients without any significant neuronal loss, despite decades of frequent generalized seizures, including episodes of status epilepticus. The authors concluded that seizures do not inevitably cause hippocampal lesion. In a series of 15 patients with idiopathic generalized epilepsy, postmortem neuropathological examination failed to disclose signs of HS, despite the long duration of epilepsy; a quantitative analysis performed in ten of these patients did not show significant differences when compared to age-matched controls ${ }^{62,63}$.

There are a few hypotheses that try to explain why surgery fails to render TLE with MTS patients seizure free in approximately one third of cases: residual hippocampus with HS in the side of surgery; contralateral hippocampal abnormalities; or presence of epileptogenic lesion beyond the resected temporal lobe ${ }^{64,65}$. Whole brain studies may help evaluating these hypotheses.

Babb $^{66}$ reported two cases of bilateral and asymmetric HS in patients submitted to autopsy. In both patients, there was bilateral hippocampal neuronal loss, although in one the neuronal loss was only confirmed in both hippocampi after cell counting, because in one side neuronal loss was mild. Mathern et al ${ }^{67}$ reported one patient who died few weeks after being submitted to surgical treatment for drug-resistant TLE. The hippocampus resected during surgery showed a pathological pattern consistent with HS, while the contralateral hippocampus, studied in the autopsy, showed an atypical pattern of HS with less marked neuronal loss when compared to the operated side. Furthermore, mossy fiber sprouting (MFS) was observed only in the surgically resected side. The authors concluded that in cases of asymmetric neuronal loss, the MFS presence was indicative of epileptogenic hippocampus.

MFS is one of the cellular abnormalities in the hippocampal formation that may indicate seizure generation in the mesial temporal structures in TLE-patients ${ }^{68-70}$. GCD in the $\mathrm{DG}^{38}$ and changes in the neuropeptide Y (NPY) network $^{31}$ are also among these abnormalities, which can be found uni or bilaterally in the hippocampi of TLE patients.

Thom et al. ${ }^{4}$ studied 25 epilepsy patients, who were submitted to postmortem pathological examination. Nine of them were seizure-free before death for periods up to 34 years. The authors aimed at studying synaptic reorganization in the DG, in order to determine if the process was bilateral; at investigating its association with several degrees of MTS and with different epileptic syndromes; and at analyzing if this reorganization persisted after long periods of seizure remission. Cellular reorganization in the DG was assessed in both hippocampi of all patients through immunohistochemistry with dynorphin (to demonstrate MFS) and NPY. Abnormal NPY patterns and bilateral MFS were observed in 15 patients, including those with unilateral and bilateral HS, whether symmetrical or asymmetrical. These findings were encountered in patients with mesial TLE and other epileptic syndromes, and also in those with long periods of seizure freedom preceding death. Still, MFS was observed in patients without HS. The authors concluded that synaptic reorganization in the DG may be a bilateral and persistent process in epilepsy patients; MFS may occur independently of the neuronal loss observed in HS; and MFS and abnormal patterns of NPY probably happen as a response to epileptic seizures and do not represent a critical factor in the generation of these seizures.

In addition to bilateral hippocampal abnormalities, temporal lesions extending beyond the hippocampus, as well as extratemporal ones, may also explain seizure recurrence after surgery in TLE with MTS patients ${ }^{64}$. In the conclusion section of their 1966 paper, Margerison and Corsellis remarked the "...need to see beyond the temporal lobes and to take into account the possible importance of damage in other parts of the brain as well"2. The injuries diagnosis associated with MTS has great clinical importance, due to its impact in response to clinical treatment ${ }^{71}$ and programming of surgery $^{72,73}$. The association of MTS plus another lesion out of the 
hippocampus constitutes dual pathology ${ }^{73,74}$, which was seen in 5 to $30 \%$ of patients with focal epilepsy and drug-resistant seizures $^{74}$. MTS may be associated with several other pathologies, such as MCD, slow growth tumors, vascular malformations, porencephaly, and gliosis ${ }^{72-76}$.

Macroscopic and microscopic abnormalities compatible with the diagnosis of MCD may coexist with MTS in TLE patients and constitute the most frequent type of dual pathology ${ }^{74}$. In the recently proposed classification of $\mathrm{FCD}^{77}$, its association with MTS is classified as type IIIa. Dysplastic abnormalities, such as cortical laminar disorganization, presence of dysmorphic neurons, and balloon cells in the temporal neocortex of TLE-MTS patients have been described ${ }^{78,79}$, although their clinical relevance and role in the epileptogenesis in these patients remain undefined ${ }^{80}$. Simultaneous recording of the hippocampus and dysplastic abnormalities in the temporal neocortex with depth electrodes and subdural strips showed that even subtle dysplastic lesions are epileptogenic ${ }^{72}$. However, is it still disputed in the literature if the coexistence of MTS and dysplastic lesions predispose to a poor surgical prognosis ${ }^{81}$, or if the resection of both lesions may lead to adequate seizure control after surgery ${ }^{80}$. In such cases, surgical decision - resection of the hippocampus, the FCD or both - must be based on clinical, neurophysiological, and neuroimaging data ${ }^{74}$.

Whether associated with MTS or isolated, MCD constitutes an important etiology of drug-resistant seizures ${ }^{71,82,83}$. Magnetic resonance imaging is the best available method for diagnosis ${ }^{84}$, although one quarter of all patients submitted to surgical treatment in whom pathological examination confirmed the diagnosis of MCD had normal preoperative magnetic resonance imaging exams ${ }^{82,84}$. MCD may thus go undetected by magnetic resonance imaging; patients with severe epilepsies of supposedly unknown causes may in fact have MCD. Whole brain pathological studies might diagnose $\mathrm{MCD}$, which were previously missed in vivo.

As well as MCD, other pathological abnormalities may be missed by usual diagnostic methods in epilepsy patients. Therefore, whole brain examination during autopsy may yield new information in these cases.

Blanc et al..$^{85}$ conducted a postmortem examination in six patients with TLE-MTS, along with three epilepsy patients without MTS, and four nonepilepsy controls. MTS was unilateral in four of them and bilateral in two. Cases with significant second or acquired pathology, such as contusional brain injury, cerebrovascular or neurodegenerative diseases, were excluded from the study. In all cases and controls, cortical and white matter regions from both hemispheres were sampled, selected according to known hippocampal afferent or efferent projection sites. A quantitative analysis of the cortical tissues was conducted in order to detect acquired neocortical pathology, including gliosis and microgliosis, by use of specific immunomarkers. Higher staining fractions were observed for all markers in the cortex and white matter, both in TLE-MTS and non-MTS epilepsy patients when compared to controls. Gliosis and microgliosis were more marked in temporal and frontal poles and orbitrofrontal cortex in epilepsy patients, without clear relation to hippocampal pathways. This paper demonstrated the presence of previously undetected cortical pathology in epilepsy patients, which might be related to factors such as cortical injury associated with seizures. These cortical abnormalities may contribute to seizure generation in these patients and, in operated TLEMTS patients, they might be factors leading to poor postoperative outcome.

There is not yet a group of patients in whom etiological diagnosis is not determined during life, despite clinical investigation and neurophysiological, neuroimaging, and laboratorial data. These patients are grouped under the expression cryptogenic epilepsy ${ }^{86}$. Particularly in such patients, neuropathological examination is often seen as the latest available resource for diagnostic conclusion. However, there are still some patients with long-standing severe epilepsies and normal whole brain neuropathological examination. In these patients, it is possible that the pathological abnormalities that cause seizures are beyond the sensitivity of the habitual neuropathological examination. They may happen in cellular, synaptic, or molecular levels. Perhaps a "new pathology" will be needed to help further identify the cause of seizures in patients with cryptogenic epilepsies.

In conclusion, postmortem whole brain neuropathological examination may help answer important questions, such as: what are the most common pathological findings in patients with refractory epilepsy?; what is the importance of lesions associated with the putative epileptogenic lesion?; what happens to the brain in chronic epilepsies, with seizures resistant to clinical and surgical treatments?; can seizures and seizure-related traumatic brain injuries bring additional morbidity to these patients?; and is there a progression of the lesion if the patient is seizure-free for a long time before death?

Studies correlating detailed clinical data of epilepsy patients with neuropathological findings will certainly offer an opportunity of answering, if not all, at least many of these questions.

\section{References}

1. Mathern GW. Challenges in the surgical treatment of epilepsy patients with cortical dysplasia. Epilepsia 2009;50:S45-S50.

2. Margerison JH, Corsellis JA. Epilepsy and the temporal lobes. A clinical, electroencephalographic and neuropathological study of

the brain in epilepsy, with particular reference to the temporal lobes. Brain 1966;89:499-530.

3. Meencke HJ, Janz D. Neuropathological findings in primary generalized epilepsy: a study of eight cases. Epilepsia 1984;25:8-21. 
4. Thom M, Martinian L, Catarino C, et al. Bilateral reorganization of the dentate gyrus in hippocampal sclerosis: a postmortem study. Neurology 2009;73:1033-1040.

5. Thom M, Zhou J, Martinian L, Sisodiya S. Quantitative post-mortem study of the hippocampus in chronic epilepsy: seizures do not inevitably cause neuronal loss. Brain 2005;128:1344-1357.

6. Wieser HG. ILAE Commission Report. Mesial temporal lobe epilepsy with hippocampal sclerosis. Epilepsia 2004;45:695-714.

7. $\quad$ Engel J Jr. Surgery for seizures. N Engl J Med 1996;334:647-652.

8. Commission on Classification and Terminology of the International League Against Epilepsy. Proposal for revised classification of epilepsies and epileptic syndromes. Epilepsia 1989;30:389-399.

9. Blumcke I, Beck H, Lie AA, Wiestler OD. Molecular neuropathology of human mesial temporal lobe epilepsy. Epilepsy Res 1999;36:205-223.

10. Sommer W. Erkrankung des Ammonshornes als aetiologisches Moment der Epilepsie. Arch Psychiatr Nervenkr 1880;10:631-675.

11. Blumcke I, Beck H, Scheffler B, et al. Altered distribution of the alphaamino-3-hydroxy-5-methyl-4-isoxazole propionate receptor subunit GluR2(4) and the N-methyl-D-aspartate receptor subunit NMDAR1 in the hippocampus of patients with temporal lobe epilepsy. Acta Neuropathol 1996;92:576-587.

12. Blumcke I, Pauli E, Clusmann H, et al. A new clinico-pathological classification system for mesial temporal sclerosis. Acta Neuropathol 2007;113:235-244.

13. Bernasconi N, Bernasconi A, Andermann F, Dubeau F, Feindel W, Reutens DC. Entorhinal cortex in temporal lobe epilepsy: a quantitative MRI study. Neurology 1999;52:1870-1876.

14. Pitkanen A, Tuunanen J, Kalviainen R, Partanen K, Salmenpera T. Amygdala damage in experimental and human temporal lobe epilepsy. Epilepsy Res 1998;32:233-253.

15. Aroniadou-Anderjaska V, Fritsch B, Qashu F, Braga MF. Pathology pathophysiology of the amygdala in epileptogenesis and epilepsy. Epilepsy Res 2008;78:102-116.

16. Meyer A, Beck E. The hippocampal formation in temporal lobe epilepsy. Proc R Soc Med 1955;48:457-462.

17. Mathern GW, Babb TL, Vickrey BG, Melendez M, Pretorius JK. The clinical-pathogenic mechanisms of hippocampal neuron loss and surgical outcomes in temporal lobe epilepsy. Brain 1995;118: 105-118.

18. de Lanerolle NC, Lee TS. New facets of the neuropathology and molecular profile of human temporal lobe epilepsy. Epilepsy Behav 2005;7:190-203

19. Pitkanen A, Nissinen J, Nairismagi J, et al. Progression of neuronal damage after status epilepticus and during spontaneous seizures in a rat model of temporal lobe epilepsy. Prog Brain Res 2002;135:67-83.

20. Pohlmann-Eden B, Gass A, Peters CN, Wennberg R, Blumcke I. Evolution of MRI changes and development of bilateral hippocampal sclerosis during long lasting generalised status epilepticus. J Neurol Neurosurg Psychiatry 2004;75:898-900.

21. Scott RC, King MD, Gadian DG, Neville BG, Connelly A. Hippocampal abnormalities after prolonged febrile convulsion: a longitudinal MRI study. Brain 2003;126:2551-2557.

22. Wiebe S, Blume WT, Girvin JP, Eliasziw M. A randomized, controlled trial of surgery for temporal-lobe epilepsy. N Engl J Med 2001;345: 311-318.

23. Engel $J$ Jr., Wiebe S, French $J$, et al. Practice parameter: temporal lobe and localized neocortical resections for epilepsy. Epilepsia 2003;44:741-751.

24. Mclntosh AM, Wilson SJ, Berkovic SF. Seizure outcome after temporal lobectomy: current research practice and findings. Epilepsia 2001;42:1288-1307.

25. Tellez-Zenteno JF, Dhar R, Wiebe S. Long-term seizure outcomes following epilepsy surgery: a systematic review and meta-analysis. Brain 2005;128:1188-1198.
26. Foldvary N, Nashold B, Mascha E, et al. Seizure outcome after temporal lobectomy for temporal lobe epilepsy: a Kaplan-Meier survival analysis. Neurology 2000;54:630-634.

27. Janszky J, Janszky I, Schulz R, et al. Temporal lobe epilepsy with hippocampal sclerosis: predictors for long-term surgical outcome. Brain 2005;128:395-404

28. Mclntosh AM, Kalnins RM, Mitchell LA, Fabinyi GC, Briellmann RS, Berkovic SF. Temporal lobectomy: long-term seizure outcome, late recurrence and risks for seizure recurrence. Brain 2004;127: 2018-2030.

29. Sisodiya SM, Moran N, Free SL, et al. Correlation of widespread preoperative magnetic resonance imaging changes with unsuccessful surgery for hippocampal sclerosis. Ann Neurol 1997;41:490-496.

30. Bruton CJ. The neuropathology of temporal lobe epilepsy. Oxford: Oxford University Press; 1988

31. de Lanerolle NC, Kim JH, Williamson A, et al. A retrospective analysis of hippocampal pathology in human temporal lobe epilepsy: evidence for distinctive patient subcategories. Epilepsia 2003;44:677-687.

32. Eriksson SH, Thom M, Bartlett PA, et al. PROPELLER MRI visualizes detailed pathology of hippocampal sclerosis. Epilepsia 2008;49: 33-39.

33. Thom M, Liagkouras I, Elliot KJ, et al. Reliability of patterns of hippocampal sclerosis as predictors of postsurgical outcome. Epilepsia 2010;51:1801-1808.

34. Jardim AP, Neves RSC, Caboclo LO, et al. Temporal lobe epilepsy with mesial temporal sclerosis: hippocampal neuronal loss as a predictor of surgical outcome. Arq Neuropsiquiatr 2012. In press.

35. Thom M, Sisodiya SM, Beckett A, et al. Cytoarchitectural abnormalities in hippocampal sclerosis. J Neuropathol Exp Neurol 2002;61: 510-519.

36. El Bahh B, Lespinet V, Lurton D, Coussemacq M, Le Gal La Salle G, Rougier A. Correlations between granule cell dispersion, mossy fiber sprouting, and hippocampal cell loss in temporal lobe epilepsy. Epilepsia 1999;40:1393-1401.

37. Blumcke I, Kistner I, Clusmann H, et al. Towards a clinico-pathological classification of granule cell dispersion in human mesial temporal lobe epilepsies. Acta Neuropathol 2009;117:535-544.

38. Houser CR. Granule cell dispersion in the dentate gyrus of humans with temporal lobe epilepsy. Brain Res 1990;535:195-204.

39. Harding B, Thom M. Bilateral hippocampal granule cell dispersion: autopsy study of 3 infants. Neuropathol Appl Neurobiol 2001;27: 245-251.

40. Houser CR, Swartz BE, Walsh GO, Delgado-Escueta AV. Granule cell disorganization in the dentate gyrus: possible alterations of neuronal migration in human temporal lobe epilepsy. Epilepsy Res 1992;9:S41-S48.

41. Sagar HJ, Oxbury JM. Hippocampal neuron loss in temporal lobe epilepsy: correlation with early childhood convulsions. Ann Neurol 1987;22:334-340.

42. Fahrner A, Kann G, Flubacher A, et al. Granule cell dispersion is not accompanied by enhanced neurogenesis in temporal lobe epilepsy patients. Exp Neurol 2007;203:320-332.

43. Thom M, Martinian L, Williams G, Stoeber K, Sisodiya SM. Cell proliferation and granule cell dispersion in human hippocampal sclerosis. J Neuropathol Exp Neurol 2005;64:194-201.

44. Blumcke I, Zuschratter W, Schewe JC, et al. Cellular pathology of hilar neurons in Ammon's horn sclerosis. J Comp Neurol 1999;414: 437-453.

45. da Silva AV, Houzel JC, Yacubian EM, et al. Dysmorphic neurons in patients with temporal lobe epilepsy. Brain Res 2006;1072:200-207.

46. Thom M, D'Arrigo C, Scaravilli F. Hippocampal sclerosis with hypertrophy of end folium pyramidal cells. Acta Neuropathol 1999;98:107-110.

47. Thom M, Martinian L, Caboclo LO, McEvoy AW, Sisodiya SM. Balloon 
cells associated with granule cell dispersion in the dentate gyrus in hippocampal sclerosis. Acta Neuropathol 2008;115:697-700.

48. Cavanagh JB, Meyer A. Aetiological aspects of Ammon's horn sclerosis associated with temporal lobe epilepsy. Br Med J 1956;2:1403-1407.

49. Thom M, Eriksson S, Martinian L, et al. Temporal lobe sclerosis associated with hippocampal sclerosis in temporal lobe epilepsy: neuropathological features. J Neuropathol Exp Neurol 2009;68: 928-938.

50. Chabardes S, Kahane P, Minotti L, et al. The temporopolar cortex plays a pivotal role in temporal lobe seizures. Brain 2005;128:1818-1831.

51. Mitchell LA, Jackson GD, Kalnins RM, et al. Anterior temporal abnormality in temporal lobe epilepsy: a quantitative MRI and histopathologic study. Neurology 1999;52:327-336.

52. Carrete H Jr., Abdala N, Lin K, et al. Temporal pole signal abnormality on MR imaging in temporal lobe epilepsy with hippocampal sclerosis: a fluid-attenuated inversion-recovery study. Arq Neuropsiquiatr 2007;65:553-560.

53. Caboclo LO, Garzon E, Oliveira PA, et al. Correlation between temporal pole MRI abnormalities and surface ictal EEG patterns in patients with unilateral mesial temporal lobe epilepsy. Seizure 2007;16:8-16.

54. Bonilha L, Rorden C, Halford JJ, et al. Asymmetrical extrahippocampal grey matter loss related to hippocampal atrophy in patients with medial temporal lobe epilepsy. J Neurol Neurosurg Psychiatry 2007;78:286-294.

55. Baulac M, De Grissac N, Hasboun D, et al. Hippocampal developmental changes in patients with partial epilepsy: magnetic resonance imaging and clinical aspects. Ann Neurol 1998;44:223-233.

56. Fernandez G, Effenberger O, Vinz B, et al. Hippocampal malformation as a cause of familial febrile convulsions and subsequent hippocampal sclerosis. Neurology 1998;50:909-917.

57. Thom M, Holton JL, D'Arrigo C, et al. Microdysgenesis with abnormal cortical myelinated fibres in temporal lobe epilepsy: a histopathological study with calbindin D-28-Kimmunohistochemistry. Neuropathol Appl Neurobiol 2000;26:251-257.

58. Sloviter RS, Kudrimoti HS, Laxer KD, et al. "Tectonic" hippocampal malformations in patients with temporal lobe epilepsy. Epilepsy Res 2004;59:123-153.

59. Spencer SS. When should temporal-lobe epilepsy be treated surgically? Lancet Neurol 2002;1:375-382.

60. Dam AM. Epilepsy and neuron loss in the hippocampus. Epilepsia 1980;21:617-629.

61. Nixon J, Bateman D, Moss T. An MRI and neuropathological study of a case of fatal status epilepticus. Seizure 2001;10:588-591.

62. Meencke HJ. Neuropathology of generalized primary epilepsy. In: Wolf P, Dam M, Janz D (eds). Advances in epileptology. Raven Press: New York; 1987, p. 1-8.

63. Meencke HJ, Veith G, Hippocampal sclerosis in epilepsy. In: Lüders H (Ed). Epilepsy surgery, Raven Press: New York; 1991, p. 705-715.

64. Hennessy MJ, Elwes RD, Binnie CD, Polkey CE. Failed surgery for epilepsy. A study of persistence and recurrence of seizures following temporal resection. Brain 2000;123:2445-2466.

65. Keller SS, Cresswell P, Denby C, et al. Persistent seizures following left temporal lobe surgery are associated with posterior and bilateral structural and functional brain abnormalities. Epilepsy Res 2007;74:131-139.

66. Babb TL. Bilateral pathological damage in temporal lobe epilepsy. Can J Neurol Sci 1991;18:645-648.

67. Mathern GW, Pretorius JK, Babb TL, Quinn B. Unilateral hippocampal mossy fiber sprouting and bilateral asymmetric neuron loss with episodic postictal psychosis. J Neurosurg 1995;82:228-233.
68. Babb TL, Kupfer WR, Pretorius JK, Crandall PH, Levesque MF. Synaptic reorganization by mossy fibers in human epileptic fascia dentata. Neuroscience 1991;42:351-363.

69. Sloviter RS. The functional organization of the hippocampal dentate gyrus and its relevance to the pathogenesis of temporal lobe epilepsy. Ann Neurol 1994;35:640-654.

70. Sloviter RS, Zappone CA, Harvey BD, Bumanglag AV, Bender RA, Frotscher M. "Dormant basket cell" hypothesis revisited: relative vulnerabilities of dentate gyrus mossy cells and inhibitory interneurons after hippocampal status epilepticus in the rat. J Comp Neurol 2003;459:44-76.

71. Semah F, Picot MC, Adam C, et al. Is the underlying cause of epilepsy a major prognostic factor for recurrence? Neurology 1998;51: 1256-1262.

72. Fauser S, Schulze-Bonhage A. Epileptogenicity of cortical dysplasia in temporal lobe dual pathology: an electrophysiological study with invasive recordings. Brain 2006;129:82-95.

73. Li LM, Cendes F, Watson C, et al. Surgical treatment of patients with single and dual pathology: relevance of lesion and of hippocampal atrophy to seizure outcome. Neurology 1997;48:437-444.

74. Li LM, Cendes F, Andermann F, et al. Surgical outcome in patients with epilepsy and dual pathology. Brain 1999;122:799-805.

75. Cendes F, Cook MJ, Watson C, et al. Frequency and characteristics of dual pathology in patients with lesional epilepsy. Neurology 1995;45:2058-2064.

76. Eriksson SH, Nordborg C, Rydenhag B, Malmgren K. Parenchymal lesions in pharmacoresistant temporal lobe epilepsy: dual and multiple pathology. Acta Neurol Scand 2005;112:151-156.

77. Blumcke I, Thom M, Aronica E, et al. The clinicopathologic spectrum of focal cortical dysplasias: a consensus classification proposed by an ad hoc Task Force of the ILAE Diagnostic Methods Commission. Epilepsia 2011;52:158-174.

78. Diehl B, Najm I, LaPresto E, et al. Temporal lobe volumes in patients with hippocampal sclerosis with or without cortical dysplasia. Neurology 2004;62:1729-1735.

79. Kalnins RM, Mclntosh A, Saling MM, Berkovic SF, Jackson GD, Briellmann RS. Subtle microscopic abnormalities in hippocampal sclerosis do not predict clinical features of temporal lobe epilepsy. Epilepsia 2004;45:940-947.

80. Thom M, Sisodiya S, Harkness W, Scaravilli F. Microdysgenesis in temporal lobe epilepsy. A quantitative and immunohistochemical study of white matter neurones. Brain 2001;124:2299-2309.

81. Palmini A, Gambardella A, Andermann F, et al. Operative strategies for patients with cortical dysplastic lesions and intractable epilepsy. Epilepsia 1994;35(Suppl):S57-S71.

82. Palmini A, Najm I, Avanzini G, et al. Terminology and classification of the cortical dysplasias. Neurology 2004;62(Suppl):S2-S8.

83. Sisodiya SM, Fauser S, Cross JH, Thom M. Focal cortical dysplasia type II: biological features and clinical perspectives. Lancet Neurol 2009;8:830-843.

84. Ruggieri PM, Najm I, Bronen R, et al. Neuroimaging of the cortical dysplasias. Neurology 2004;62(Suppl):S27-S29.

85. Blanc F, Martinian L, Liagkouras I, Catarino C, Sisodiya SM, Thom M. Investigation of widespread neocortical pathology associated with hippocampal sclerosis in epilepsy: a postmortem study. Epilepsia 2011;52:10-21.

86. Berg AT, Berkovic SF, Brodie MJ, et al. Revised terminology and concepts for organization of seizures and epilepsies: report of the ILAE Commission on Classification and Terminology, 2005-2009. Epilepsia 2010;51:676-685. 